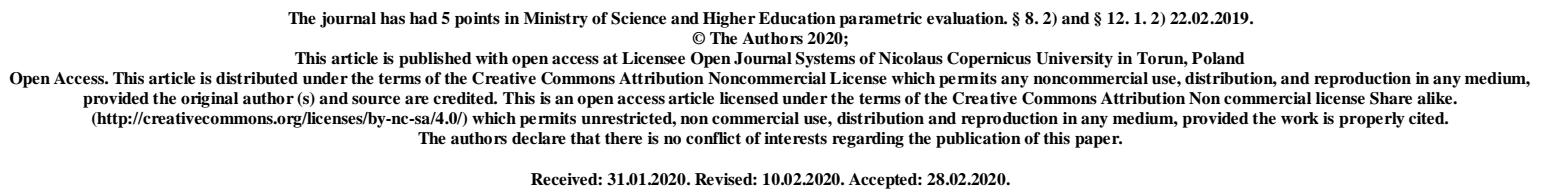

UDK 616.131-008.331.1-06.616.127-008

\title{
MORPHOMETRIC ANALYSIS OF STRUCTURAL ARRANGEMENT OF THE TESTIAL ARTERIES IN POSTRESECTIONAL ARTERIAL PULMONARY HYPERTENSION
}

\author{
S. O. Konovalenko
}

Ternopil National Medical University

named after I. Ya. Gorbachevsky Ministry of Health Ukraine

\section{Abstracts}

Introduction. Removal of the right or left lung can lead to postresection pulmonary arterial hypertension, venous stasis in the organs of the great circle of blood circulation and structural and functional changes in them. Morphological changes in endothelial cells of arteries of testes in postresection pulmonary arterial hypertension are insufficiently studied.

Objective of the research: to study features of structural reorganization of testicular arteries at postresection pulmonary arterial hypertension.

Materials of the research and their discussion. Morphological methods were used to study the structural rearrangement of the testicular arteries of 40 rats, which were divided into 3 groups. The 1st group included 11 intact animals, the 2nd - 19 rats with arterial hypertension in the small circulation and compensated pulmonary heart, the 3rd - 10 experimental animals with pulmonary arterial hypertension and decompensated pulmonary heart. Postresection pulmonary arterial hypertension and pulmonary heart were modeled by performing right pulmonectomy in rats. One month after the start of the experiment, rats were 
euthanized by bloodletting under conditions of thiopental anesthesia. A separate weighing of the chambers of the heart, their planimetry. Pieces were cut from the testicles, which were fixed in $10 \%$ formalin solution, passed through ethyl alcohols of increasing concentration and placed in paraffin. Microtome sections after dewaxing were stained with different dyes. In the left and right testes, the outer and inner diameters of small-caliber arteries, media thickness, Kernogan index, endothelial cell height, diameter of their nuclei, nuclear-cytoplasmic ratios in endotheliocytes, and relative volume of damaged cells were measured. Quantitative indicators were processed statistically.

Results of the research and their discussion. Morphometrically, it was found that with decompensation of the postresection pulmonary heart, the lumen of the small-caliber arteries of the left testicle decreased by $12.6 \%$. the Kernogan index - by $11.7 \%$, and the right - by 9.5 and $9.9 \%$, respectively. The relative volume of damaged endothelial cells of the studied vessels in right ventricular failure increased 11.6 times, and the right -9.3 times.

Histological examination of the testicles micropreparations of experimental animals after right-sided pulmonectomy showed severe vascular disorders (plethora of mostly venous vessels of the microhemocirculatory tract, stasis, thrombosis, diapedetic perivasal hemorrhage), stromal and perivasal edema, noncystic edema, dystrophy, dystrophy.

Conclusions. It is established that in the conditions of the simulated pathology the wall thickens markedly, the lumen of the studied arteries narrows, endotheliocytes are damaged, structural cellular homeostasis is disturbed, which is complicated by their dysfunction, deterioration of blood supply, hypoxia, dystrophic, necrobiotic lesions. Structural changes in the arteries predominated in the left testis and in pulmonary heart decompensation.

\section{Key words: arteries; testis; rats; pulmonary arterial hypertension.}

Introduction. Pneumonectomy is often performed today in modern surgical clinics for benign and malignant tumors, metastases, injuries, tuberculosis, alveolar echinococcosis, lung transplantation [1, 3, 7]. Removal of the lung can lead to various post-resection complications: hypertension in the small circulation, pulmonary heart, cardiovascular failure, arrhythmias, postpneumonectomy edema of the single lung, thromboembolism of the branches of the pulmonary artery, postpneumonectomy syndrome [12]. Postresection pulmonary arterial hypertension leads to structural rearrangement of the circulatory system, abdomen and pelvis, as well as remodeling of their structures. The testis belongs to the organs whose hemodynamic disorders are complicated by various morphological changes in the vascular bed and their structures. It should be noted that the peculiarities of testicular vascular 
remodeling in postresection pulmonary arterial hypertension have been insufficiently studied $[1,2,4,9]$.

In recent years, morphologists are increasingly using morphometric research methods that allow quantitative and most objective assessment of various physiological and pathological processes in organs and systems and logically interpret them [6].

Objective of the research: to study features of structural reorganization of testicular arteries at postresection pulmonary arterial hypertension.

Materials of the research and their discussion. The complex of morphological methods studied the features of structural rearrangement of the arteries of 40 white male rats, which were divided into 3 groups: 1st group included 11 intact healthy experimental animals (control), which was in normal vivarium conditions, 2nd - 19 rats with arterial hypertension in the small circle of blood circulation and compensated pulmonary heart, 3rd - 10 experimental animals with pulmonary arterial hypertension and decompensated pulmonary heart. The latter was confirmed by shortness of breath, cyanosis of the mucous membranes, hydrothorax, hydropericardium, congestion in the circulatory system. Postresection pulmonary arterial hypertension and pulmonary heart were modeled by performing right-sided pulmonectomy in rats $[1,6]$. Surgical interventions were performed under thiopental anesthesia in accordance with the rules of asepsis and antiseptics. One month after the start of the experiment, rats were euthanized by bloodletting under conditions of thiopental anesthesia. The heart was cut according to the method of GG Avtandilov, performed a separate weighing of the heart chambers, their planimetry $[2,5]$. Pieces were cut from the testis, which were fixed in $10 \%$ formalin solution, passed through ethyl alcohols of increasing concentration and placed in paraffin. Microtome sections after deparaffinization with hematoxylin-eosin, by the method of van Gizon, Mallory, Heidenhain, Weigert [7].

Morphometrically, small-caliber arteries (outer diameter 26-50 $\mu \mathrm{m}$ ) were studied in the left (LT) and right testicles (RT) of experimental animals [6]. The outer (DO) and inner (DI) diameters of the vessels, the thickness of the media (TM), the Kernogan index - KI (the ratio of the area of the lumen to the area of the vessel), the height of endotheliocytes (HE), the diameter of their nuclei (DNE), nuclear cytoplasmic the ratio in endothelial cells (NCE), the relative volume of these damaged cells (RVD) [5, 6]. Morphometric measurements were performed using the program "Video-Test-5.0". Quantitative indicators were processed statistically. Processing of results was performed in the department of system statistical researches of Ternopil National Medical University named after I. Gorbachevsky of the 
Ministry of Health of Ukraine in the software package STATISTIKA. The difference between the comparative values was determined by the Mann-Whitney and Student test $[5,8]$.

Results of the research and their discussion. Separate weighing of parts of the heart and their planimetry showed that a month after right-sided pulmonectomy there was hypertrophy of the chambers of the heart and their expansion with a predominance of the mass of the right ventricle and its dilatation, ie pulmonary heart. The findings indicated the development of pulmonary arterial hypertension and pulmonary heart [2]. Morphometry revealed a pronounced structural rearrangement of small caliber arteries in the testes. Morphometric parameters obtained as a result of the study are presented in the table. Analysis of the data in this table revealed that postresection pulmonary hypertension led to a significant structural adjustment of the studied vessels. Thus, the outer diameter of the small-caliber arteries of the left testis in the compensated pulmonary heart increased statistically significantly $(\mathrm{p}<0.05)$ by $3.4 \%$, and in its decompensation - by $4.8 \%$. The thickness of the media of these vessels also increased markedly. In the 2nd group of observations, this morphometric parameter with a high degree of reliability $(\mathrm{p}<0.01)$ increased by $7.0 \%$, and in the 3rd group (decompensated pulmonary heart) - by $15.5 \%$. The inner diameter of the smallcaliber testicular arteries in the compensated pulmonary heart decreased from $(24.50 \pm 0.21)$ to $(22.60 \pm 0.18) \mu \mathrm{m}$. These morphometric parameters were statistically significant $(\mathrm{p}<0.001)$ differed from each other and the last numerical value was lower than the previous one by $7.7 \%$.

At decompensation of pulmonary heart the revealed decrease in a gleam of investigated vessels was equal to $12,5 \%$. The Kernogan index of the studied vessels changed significantly in these experimental conditions. Thus, in compensated pulmonary heart, this morphometric index decreased by $7.5 \%$, and in right ventricular failure - by $11.7 \%$. It should be noted that most researchers believe that the Kernogan index reflects the physiological capacity of the arteries [5, 6], and its decrease indicates a significant disruption and deterioration of blood supply to the body.

The height of endothelial cells of the studied vessels and nuclei of the left testis in postresection arterial pulmonary hypertension and compensated pulmonary heart changed little. The nuclear-cytoplasmic index of the studied cells was almost unchanged, which indicated the stability of structural cell homeostasis [5,9]. In the 3rd group of observations, the height of endothelial cells decreased by $2.8 \%$, and the diameter of their nuclei increased by $1.3 \%$, which led to pronounced changes in the nuclear-cytoplasmic relationship in these c cellular homeostasis [5]. The relative volume of damaged endothelial cells in the small- 
caliber arteries of the left testis in the compensated pulmonary heart increased 2.55 times $(\mathrm{p}<0.001)$, and in the conditions of pulmonary heart decompensation -11.6 times $(\mathrm{p}<0.001)$.

Table - Morphometrine characteristics of small-caliber testicular arteries of experimental animals $(\mathrm{M} \pm \mathrm{m})$

\begin{tabular}{|l|c|c|c|}
\hline \multirow{2}{*}{ Indicator } & \multicolumn{3}{|c|}{ Group of animals } \\
\cline { 2 - 4 } & $1 \mathrm{st}$ & 2nd & 3rd \\
\hline DOLT, $\mu \mathrm{m}$ & $38,30 \pm 0,42$ & $39,60 \pm 0,39^{*}$ & $40,15 \pm 0,36^{* *}$ \\
\hline DILT, $\mu \mathrm{m}$ & $24,50 \pm 0,21$ & $22,60 \pm 0,18^{* *}$ & $21,40 \pm 0,15^{* * *}$ \\
\hline TMLT, $\mu \mathrm{m}$ & $7,10 \pm 0,12$ & $7,60 \pm 0,09^{* *}$ & $8,20 \pm 0,12^{* * *}$ \\
\hline KILT, $\%$ & $40,10 \pm 0,45$ & $32,60 \pm 0,36^{* * *}$ & $28,40 \pm 0,27^{* * *}$ \\
\hline HELT, $\mu \mathrm{m}$ & $6,10 \pm 0,09$ & $6,08 \pm 0,08$ & $5,93 \pm 0,05$ \\
\hline DNELT, $\mu \mathrm{m}$ & $3,12 \pm 0,03$ & $3,09 \pm 0,03$ & $3,16 \pm 0,03$ \\
\hline NCELT & $0,262 \pm 0,003$ & $0,258 \pm 0,003$ & $0,282 \pm 0,003^{* *}$ \\
\hline RVDLT, $\%$ & $2,10 \pm 0,02$ & $4,30 \pm 0,05^{* * *}$ & $24,50 \pm 0,27^{* * *}$ \\
\hline DORT, $\mu \mathrm{m}$ & $37,57 \pm 0,42$ & $38,76 \pm 0,36^{*}$ & $38,84 \pm 0,36^{*}$ \\
\hline DIRT, $\mu \mathrm{m}$ & $24,52 \pm 0,21$ & $23,10 \pm 0,21^{* *}$ & $22,20 \pm 0,18^{* * *}$ \\
\hline TMRT, $\mu \mathrm{m}$ & $7,06 \pm 0,12$ & $7,40 \pm 0,12^{*}$ & $7,66 \pm 0,12^{* *}$ \\
\hline KIRT, $\%$ & $42,50 \pm 0,45$ & $35,50 \pm 0,36^{* * *}$ & $32,60 \pm 0,33^{* * *}$ \\
\hline HERT, $\mu \mathrm{m}$ & $6,10 \pm 0,12$ & $6,08 \pm 0,09$ & $5,96 \pm 0,03^{*}$ \\
\hline DNERT, $\mu \mathrm{m}$ & $3,09 \pm 0,04$ & $3,10 \pm 0,03$ & $3,14 \pm 0,03$ \\
\hline NCERT & $0,256 \pm 0,003$ & $0,260 \pm 0,003$ & $0,268 \pm 0,002^{*}$ \\
\hline RVDRT, $\%$ & $2,08 \pm 0,04$ & $3,90 \pm 0,03^{* * *}$ & $19,40 \pm 0,18^{* * *}$ \\
\hline
\end{tabular}

Note. $*_{-}$p $<0,05 ; * *$-p $<0,01 ; * * *$-p $<0,001$, compared with the 1 st group

Morphometric parameters of the arteries of small caliber of the right testis changed similarly, but to a lesser extent than the previous ones. Thus, the outer diameter of the studied vessels in the compensated pulmonary heart statistically significantly $(\mathrm{p}<0.05)$ increased by $3.1 \%$, and with its decompensation - by $3.4 \%$. The thickness of the media increased by 4.8 $(\mathrm{p}<0.05)$ and $8.5 \%(\mathrm{p}<0.01)$, respectively. The inner diameter of small caliber arteries and the Kernogan index under these experimental conditions decreased. With compensated pulmonary heart, the lumen of the studied vessels decreased by $5.8 \%(\mathrm{p}<0.01)$, and with right ventricular heart failure - by $9.5 \%(\mathrm{p}<0.001)$. The Kernogan index in these experimental conditions was reduced by $7.0 \%$ and $9.9 \%$, respectively $(\mathrm{p}<0.001)$.

The height of endothelial cells and the diameters of the nuclei of small-caliber arteries of the right testis in the compensated pulmonary heart varied slightly. Nuclear-cytoplasmic ratios in endothelial cells did not change. In the 3rd group (decompensated pulmonary heart) by $4.7 \%(\mathrm{p}<0.05)$ increased nuclear-cytoplasmic ratio. The found changes of the studied morphometric index testified to the expressed disturbance of cellular structural homeostasis in 
endotheliocytes $[5,9]$. The findings were also confirmed by the relative volume of damaged endothelial cells in the studied arterial vessels of the right testis. With pulmonary heart compensation, this morphometric index increased 1.9 times $(\mathrm{p}<0.001)$ compared with the same control value, and with right ventricular failure - 9.3 times $(\mathrm{p}<0.001)$. The obtained data show that in the left testis the remodeling of small caliber arteries in hypertension in the small circle of blood circulation was more pronounced in comparison with the right one, which can be connected with the peculiarities of venous outflow from it [10].

Histological examination of the testicles micropreparations of experimental animals after right-sided pulmonectomy showed severe vascular disorders (plethora of mostly venous vessels of the microhemocirculatory tract, stasis, thrombosis, diapedetic perivasal hemorrhage), stromal and perivasal edema, noncystic edema, dystrophy, dystrophy.

In some places in the micropreparations of the testicles there was also an increase in connective tissue. Locations of necrotized cells were replaced by connective tissue and sometimes adipose tissue. In some of the studied arteries there was a proliferation of endothelial cells, which in some places led to obliteration of the lumen of blood vessels. The walls of the arterial vessels of the testicles are thickened, their lumen is narrowed, endothelial cells are dystrophically altered, in places desquamated, perivasal tissues with severe edema and focal infiltrates. In some arteries destruction of membranes, structural changes of myocytes, the phenomenon of a myoelastofibrosis was noted. The detected pathohistological changes dominated in the left testicle.

Recently, researchers are paying more and more attention to the condition of endothelial cells in various pathological conditions. The latter are an active endocrine organ that synthesizes various biologically active substances necessary for the regulation of vital body processes (blood clotting, vascular tone, functional activity of the kidneys, heart rate, diffusion of water, ions, metabolic products). Endothelial cells also perform barrier, hemostatic, rheological, producing, metabolic, transport, and reparative functions. They play an important role in the remodeling of the vascular wall, ie in changes in its structure and function in various physiological and pathological conditions. Endothelial cells also synthesize nitric oxide (NO), an endothelial substance that relaxes blood vessels. It follows that the violation of the structure of a significant number of endothelial cells leads to their dysfunction, blockade of NO synthase, reduced NO synthesis and activation of its degradation processes $[6,11]$. These phenomena are accompanied by spasm and vasoconstriction, which not only supports but also exacerbates hypoxia, edema, dystrophy and necrobiotic changes in cells and tissues with subsequent infiltration and development of multiple sclerosis. 
Conclusions. Prolonged postresection arterial pulmonary hypertension leads to a pronounced structural rearrangement of small testicular arteries, which is characterized by thickening of the vessel wall, narrowing of their lumen and endothelial cell lesions, endothelial dysfunction, deterioration of blood supply to the studied organ and ciliate. The detected pathomorphological changes dominated in the left testis and in pulmonary heart decompensation.

\section{References}

1. K. M. Amosova, L. F. Konoplyova, I. D. Mazur. Clinical course and condition of the myocardium with chronic pulmonary heart due to chronic obstructive pulmonary pathology depending on the presence of pulmonary hypertension. Heart and blood vessels. 2009. №2. P. 48-52.

2. L. V. Tatarchuk. Morphometric analysis of heart chambers remodeling after pulmonectomy. Achievements of clinical and experimental medicine. 2011. № 2 (15). P. 123126.

3. J. Simonnean, N. Galie, L. Rubin. Clinical classification of pulmonary hypertension. Y. Am. Cell. Cardiol. 2014. №12. P. 55-125.

4. B. L. Truskavetsky. Comparison of echocardiographic and radiological methods in the diagnosis of pathological changes of the right ventricle. Scientific Bulletin of Uzhgorod University, series "Medicine" . 2011. Issue 40. P. 148- 151.

5. G. G. Avtandilov. Fundamentals of quantitative pathological anatomy. M. Medicine. 2002. 268 p.

6. M. S. Hnatyuk, L. V. Tatarchuk, O. B. Slabyi. Morphometric assessment of features of remodeling of ventricular arteries in post-resection arterial pulmonary hypertension. Bulletin of problems biology and medicine. 2011. Issue 2, Vol.2. P. 57-60.

7. L. P. Horalskyy, V. T. Khomych, O. I. Kononskyy. Fundamentals of histological technique and morphofunctional research methods in normal and in pathology. Zhytomyr. Polissya. 2011. 288 p.

8. S. N. Lapach, A. V. Gubienko, P. N. Babich. Statistical Methods in Biomedical Research Excell. Kiev. Morion. 2001. 410 p.

9. L. M. Nepomnyashchikh. Morphogenesis of the most important general pathological processes in the heart. Novosibirsk: Nauka. 2001. 352 p.

10. B. V. Hrytsulyak, A. M. Spaska, V. B. Hrytsulyak. Orchoepididymitis. IvanoFrankivsk. Precarpathian National University. 2010. 188 p. 
11. Kh. I. Vozna, V. D. Moskalyuk, V. D. Sorokhan. Endothelium: functional properties and its dysfunction (review of literature with materials of own researches). Clinical and experimental pathology. 2015. Vol. 14, № 1. P. 209-214.

12. O. B. Slabyi. Morphogenesis of postresection of corpulmonale. Hospital surgery. Kovalchuk Magazine. 2017. № 3. P. 109-113 